\title{
Architecture of an Education and Research Network: Case of TogoRER
}

\author{
Eyouléki Tcheyi Gnadi Palanga ${ }^{1}$, Koffi Sagna ${ }^{2,}$, Koffi Mawugno Kodjo ${ }^{1}$, \\ Abalo Mazoudom Kondo-Adi ${ }^{1}$, Koffi-Sa Bédja ${ }^{1}$ \\ ${ }^{1}$ Research Team in Engineering Sciences, National School of Engineers, University of Lomé, Lomé, Togo \\ ${ }^{2}$ Laboratory on Solar Energy, Physics Department, Sciences Faculty, University of Lomé, Lomé, Togo
}

Email address:

vpalanga@univ-lome.tg (E. T. G. Palanga), ksagna@univ-lome.tg (K. Sagna), kkodjo@univ-lome.tg (K. M. Kodjo),

vtkondoadi@gmail.com (A. M. Kondo-Adi)

${ }^{*}$ Corresponding author

\section{To cite this article:}

Eyouléki Tcheyi Gnadi Palanga, Koffi Sagna, Koffi Mawugno Kodjo, Abalo Mazoudom Kondo-Adi, Koffi-Sa Bédja. Architecture of an Education and Research Network: case of TogoRER. American Journal of Modern Physics. Vol. 8, No. 1, 2019, pp. 5-13.

doi: 10.11648/j.ajmp.20190801.12

Received: November 2, 2018; Accepted: November 21, 2018; Published: April 2, 2019

\begin{abstract}
Information and communication technologies (ICTs) have integrated all fields of activity today with a real effect on research and education. Thus, this has led the education and research community to build a global network of standards to take full advantage of the related benefits. Indeed, to propose an architecture of a solid education and research network especially for our country is to give a preliminary basis that would help in an efficient realization when our governments decide to support the creation of a national research and education network to stimulate the research. It is in this perspective that the education and research networks (RERs) have emerged. Through a study on the level of Internet coverage of the different public and private structures of higher education and research, based on national data collections and revealing a lack of adequate bandwidth, our investigations allowed to define a network architecture that can be implemented for the needs of education and research in Togo. This allows researchers, teachers and students to share information online, quickly and reliably. Its users are thus able to cooperate more effectively and have easier access to the best available resources. For this study, which concerns the case of Togo, the objective of this paper is to define and implement a better architecture of Togo's education and research network (TogoRER), which will be interconnected to the education and research network of West and Central Africa (WACREN) according to the national technical realities while drawing on the experience of certain countries, hence the problematic of this theme.
\end{abstract}

Keywords: TogoRER, Commercial Internet, Optical Fiber, Networks, Architecture, NREN, NOC

\section{Introduction}

Information and communication technologies (ICTs) have become a very important tool in all human activities and the world of research is no exception to this rule nowadays [1]. The digital divide that characterizes the north and the south is also reflected in a lack of access to modern infrastructure, which is essential in the field of higher education and research in Africa in general and more specifically in West Africa [2] and the Center.

This state of affairs is a barrier to interoperability between education and research structures in this part of Africa and their counterparts around the world. In addition, the difficulties of accessing scientific resources available elsewhere and the exchange of information for the advancement of education and research in educational and research structures in these two regions of Africa is partly due to the absence or the inadequacy of a reliable technological infrastructure which is the essential carrier vector [3]. Today, this has an impact on areas of research and higher education that depend on access to robust and reliable platforms. This is a concern for most educational and research institutions in West and Central Africa and more specifically those in Togo. 
The 2010s were characterized by the establishment of NRENs (National Research and Education Netwoks) in West and Central Africa. In Togo, this establishment of TogoRER aims to take advantage in the exchange of information and resources.

The purpose of TogoRER is to build a digital communication infrastructure for Education and Research by interconnecting the national research community and higher education to other education and research networks at the regional, African and international levels to take advantage of the benefits of this global education and research network. This is not a simple matter of improving internet connection. It is especially in the case of Togo to connect to the large network of research and higher education by creating its national Research and Education Network (REN) which will link the institutions of research and higher education.

Therefore, a researcher working on a specific subject can easily access certain results already available elsewhere, allowing him a rapid advance; it can also use powerful computing or modeling platforms available elsewhere and produce its own results. In short, the user accesses scientific resources that he does not have close access in his geographical area or in the context of the commercial Internet $[4,5]$.

This type of network will also provide learners with specific sources of information that are available and accessible at all times. This can contribute to improving the success rate in higher education.

Basing on this, all the importance of architecture of an education and research network proposed in this paper for the case of Togo, is to allow researchers, teachers and students from Togo and other developing countries in the same needs to share information online, quickly and reliably. Indeed, after showing the context and the real problem that the investigations presented in this paper try to solve, the method used to collect information, the knowledge on the subject will be presented. Then, the results will be given through different architectures for the case of Togo and this can be applied to other developing countries.

\section{Context and Problem}

The context of Information and Communication Technologies for Development (ICT4D) programs calls for the establishment of research and education networks as a means of achieving economies of scale, reducing the costs of bandwidth and facilitate sharing of the rare available bandwidth [7]. The ultimate goal, however, goes beyond infrastructure, cost and bandwidth (although it remains a high priority in Africa). Indeed, the goal is to foster the development of human networks that lead to research collaborations at the national, regional and continental levels. This requires an in-depth study of the business plan, the development of a resource mobilization strategy, and negotiations with fiber optic network owners.

The capacity building, conducted in partnership with the African Network Operators Group (AfNOG) and AfriNIC (the Regional Internet Registry for Africa), will focus on network management and bandwidth optimization on campus. However, it should be noted that the establishment of a national network of education and research is not easy because the objectives of different stakeholders in the development of the NREN economic model are very different. Academic institutions want affordable Internet and advanced services, the government wants to see a sustainable NREN and telecom operators see more current and future business opportunities. The different objectives are not always coherent and an iterative and joint process is proposed.

The concept of NREN and its features are progressively being developed in a way that leads to the ultimate goal: a strong NREN financial model endorsed and supported by all stakeholders [6].

Having easy access to information and knowledge is a prerequisite for the creation of new knowledge. This is not a new fact; it was done in the past through documentary collections such as books and magazines. However, online resources nowadays have become for teachers, researchers and learners a key way to access the impressive amounts of information available on the Internet. Therefore, adequate network infrastructure with sufficient bandwidth is crucial for education and research.

While the education and research communities in both developed and emerging countries benefit fully from the research and education networks (REN), higher education institutions (HEIs) and research institutions in Africa are late in this process because of the lack of adequate access to the necessary infrastructure.

As Michael Foley of the World Bank points out: The arrival of undersea fiber optic cables along the eastern and western coasts of Africa over the last decade has undoubtedly contributed to the growth of RENs and caused a considerable reduction in Internet access costs [8].

It is in this sense that HEIs around the world have set up a global network known as the Research and Education Network (REN). For each country, the different member institutions must have their network at the national level, which in turn is interconnected to the regional network and the latter is connected to the global network.

In Togo, the various institutions intervening in the Superior have regrouped in order to have their own national network called TogoRER.

What are the national technical requirements?

What opportunities to seize to set up this type of network in a logical and physical way?

The answers to these questions will help to evaluate and define an adequate network architecture that can meet the needs of TogoRER.

\section{Methodology}

\subsection{Method Used to Collect Information}

This study is specifically based on the case of Togo, in 
order to determine the best architecture of the TogoRER network taking into account the national technical constraints.

To do this, it was necessary to collect data on the different options that can be offered in terms of the design and implementation of a topology of a very high speed broadband network at the national level. These data we needed are:

a The availability of optical fibers at the national level;

b The possibilities of sponsoring (free allocation) of unused fibers;

c Direct optical fiber drawing amounts from one point to another to have a very independent network;

d And finally, the amount of fiber laying last mile based on the fiber optic network of an existing operator.

To obtain the information on these different headings, we met face-to-face technical service heads with regard to the points that are technical, and then the heads of commercial services for the aspects concerning the amounts.

We also had to consult the proposals for tenders launched by the operator Togo Telecom (Telecommunication Operator of Togo) for the realization of the laying of its fibers across the country. The proposals of different service providers, and then the amounts of the lowest

Claimants served as the basis for the amounts in this study.

It should be noted that Togo telecom is the only operator that has a fiber optic mesh covering virtually the entire Togolese territory and therefore the only one able in this context to provide this service at lower cost.

\subsection{The Knowledge on the Subject}

The results of the various studies conducted by the African Universities Association (AUA) dismantle a large bandwidth deficit at the level of HEIs in the region of Central and West Africa. This deficit is by no means a peculiar situation for academic institutions, but more broadly reflects the structure of the Internet bandwidth supply chain to Africa [9].

If for the moment the networks like UBUNTUNET in Eastern and Southern Africa, then EUMEDCONNECT for North Africa have already done their experiments; West and Central Africa is following suit. It is therefore important to move West and Central Africa rapidly in this direction.

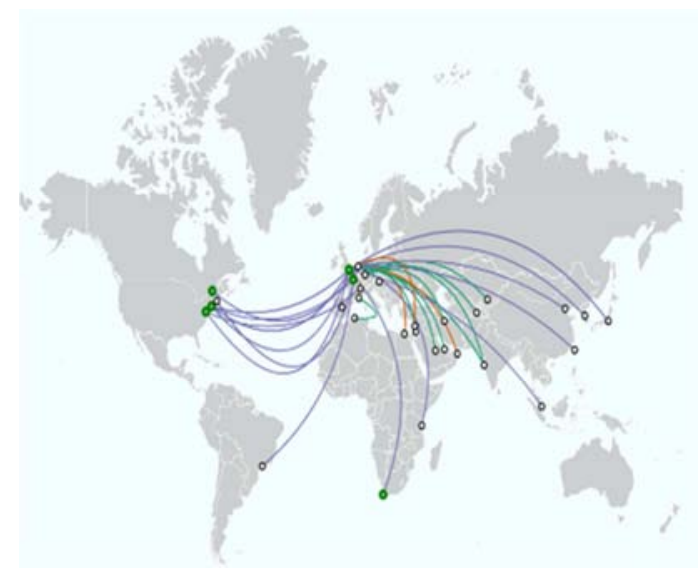

Figure 1. Overview of the worldwide RERs interconnection [8].
As illustrated in Figure 1, when it comes to the connectivity of West and Central Africa to the global education and research network, there is still a big gap.

Hence a need to fill this digital gap in terms of access to different broadband networks to strengthen the teaching capacity of the various institutions in Africa and more specifically in West and Central Africa.

Initiatives are then underway according to the different African regions.

Indeed, the goal is to foster the development of human networks that lead to research collaborations at the national, regional and continental levels. This requires an in-depth study of the business plan, the development of a resource mobilization strategy, and negotiations with optical fibers network owners.

The capacity building, conducted in partnership with the African Network Operators Group (AfNOG) and AfriNIC (the Regional Internet Registry for Africa), will focus on network management and bandwidth optimization on campus [10].

Studies have addressed the issue of access and connectivity to broadband infrastructure and especially to education and research networks.

But ten years after the realities have largely evolved in these parts of Africa in general and in particular in Togo on which our study is based.

Thus, in Togo particularly, the subject of the study and setting up an education and research network is a new subject around whom debates are beginning conducted with the objective to its implementation.

So the current methodology of this study to set up this network is a pioneer and cannot draw its source from any strengths or limitations of previous methodologies on the subject.

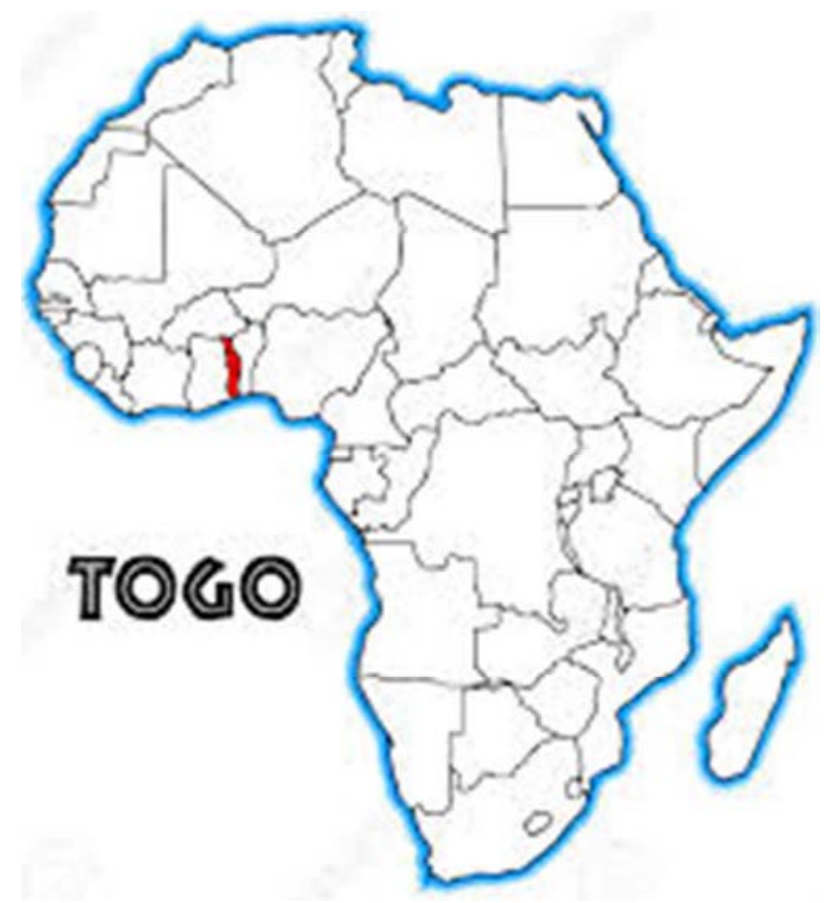

Figure 2. Illustration of Togo (TogoRER) on Africa map. 
The construction of a research and education network as being a new subject in Togo, it fully justify this study whose purpose is to provide to various members of higher education and research of Togo (Figure 2), the technological tools of tip to boost them to the best results.

To do this, the study was structured around the following points (different stages):

a Identify the benefits underlying the establishment of such a network;

b Clear the constraints in terms of national regulations for electronic communications;

c Study the cases (approaches) of countries that have already succeeded in setting up such networks

d Make different architectural proposals for the case of Togo, while taking into account the constraints mentioned above.

The advantages of setting up such a network can be divided into two categories, namely:

For users:

This network will introduce an additional motivation for students on one hand and on the other hand constitute another educational means for teachers [11]. Other benefits for users include:

a Easy access to educational resources;

b E-learning (access to several specialties);

c Scientific collaboration with researchers from other horizons;

d Access to online laboratories (online simulation);

e Promotion of online courses, use of videoconferencing;

f Improved time management;

$\mathrm{g}$ Free use of the phone on the network;

$\mathrm{h}$ Participation in different global research projects;

i Access to Eduroam (roaming Internet access);

For the institutions:

This type of network will mainly promote collaborative work between the different member institutions [12]. Other benefits for institutions include:

a Have infrastructure for interconnection (equipment, transmission medium);

b Improve the governance of higher education;

c Have sufficient Internet bandwidth (at a very low price);

National constraints:

In the developed countries, as fiber drawing started a long time ago and given the level of density of operators' optical fiber networks at the national level, it is easier for NREN in these countries to build their network on direct optical fibers; requesting and obtaining unused optical fibers from different operators, which allows them to guarantee very high speed in their infrastructure.

At opposite, African countries in general, and particularly those in West and Central Africa including Togo, where it is now that the optical fiber drawing is becoming important, it is not easy for National REN (NRENs) to build their networks using direct fibers.

Commercial Internet from different ISPs is somehow expensive: higher education institutions with small budgets cannot be able to buy high-capacity links given the large number of users (Teachers-Researchers, students, administrative and technical staff).

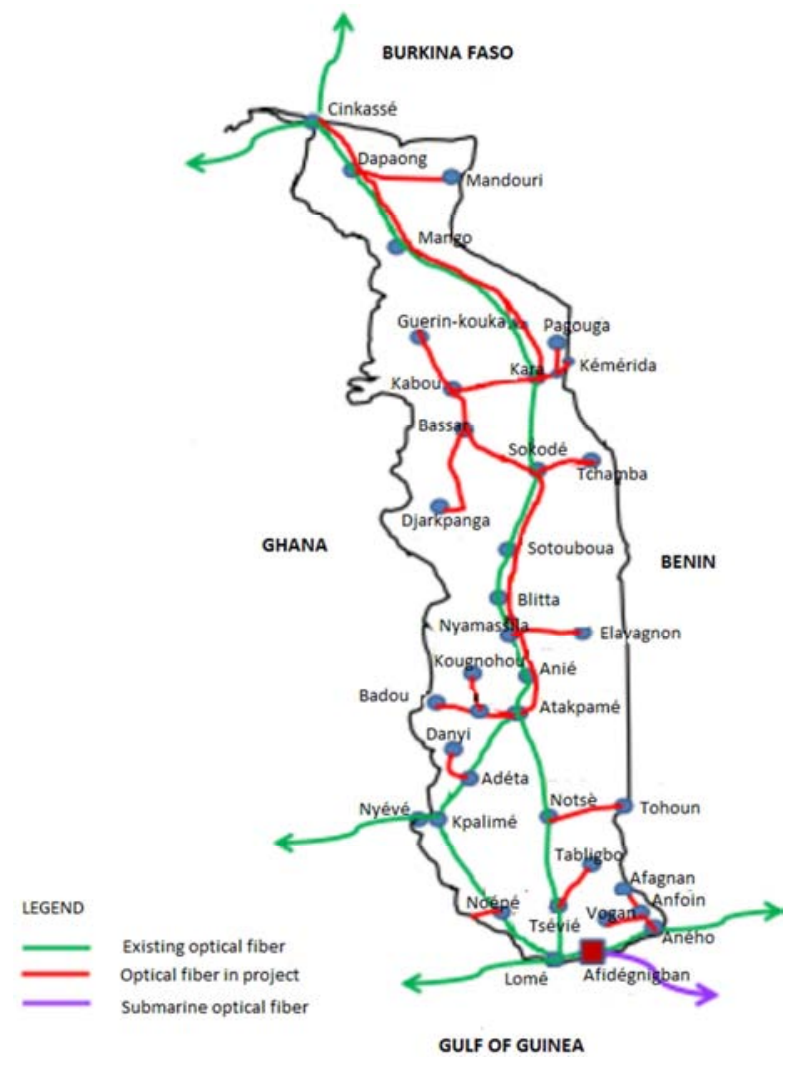

Figure 3. National optical fiber coverage of the TOGOTELECOM Operator ${ }^{l}$.

The lack of interconnection between campus networks (point-to-point links) between different higher education institutions makes difficult some resources pooling (databases, research results, access to research platforms...); unless agreements exist to go through VPNs over the commercial Internet, these are subject to the agreements and low commercial internet debits Figure 3 shows the synoptic diagram of the inter connectivity of the TogoRER network. In order to achieve this objective, an evaluation of different possibilities should be made to determine how to implement the "TogoRER service network".

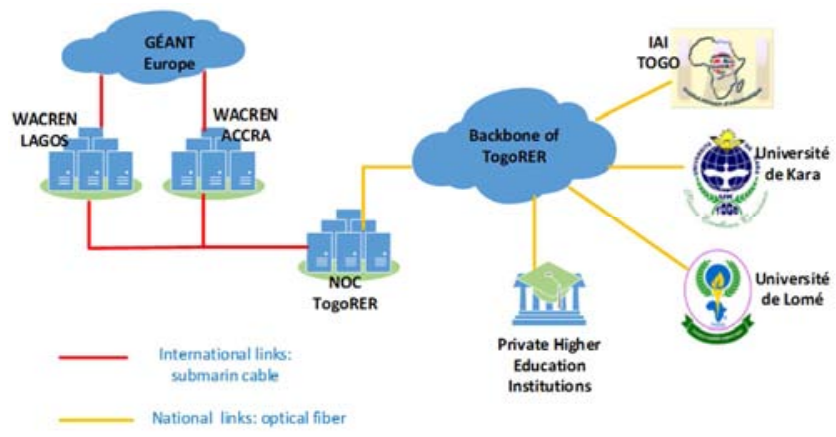

Figure 4. Synoptic of TogoRER network.

1 Source : TOGO TELECOM Documentation 


\section{Results and Discussion (Make Different Architecture Proposals for the Case of Togo)}

Higher education in Togo is made up of public higher education institutions and private ones. The public and private HEIs that are the subject of this article are the first members of TogoRER around whom this network is built.

Likewise, all other HEIs that manifest their will could later be integrated into this network as this is built to be scalable.

Figure 5 shows below the first proposed topology of national and international interconnection of TogoRER's backbone and its member institutions. The links are made of direct optical fiber from the backbone of TogoRER to different member institutions.

Optical fiber is the best transmission medium for large volume of data and at a very high speed nowadays [13]. The membres are:

UL (University of Lomé), UK (University of Kara), IAI (African Institute of Computer Science), ESAG-NDE (School of Administration and Management Our Lady of the Church), ESIBA (Higher School of Computer Science, Business and Administration), ESGIS (School of Management, Computer Science and Sciences), UCAO-UUT (Catholic University of West Africa), DRST (Center of Scientific and Technical Research), DEFITECH Polytechnic Institute, School of Cadres.

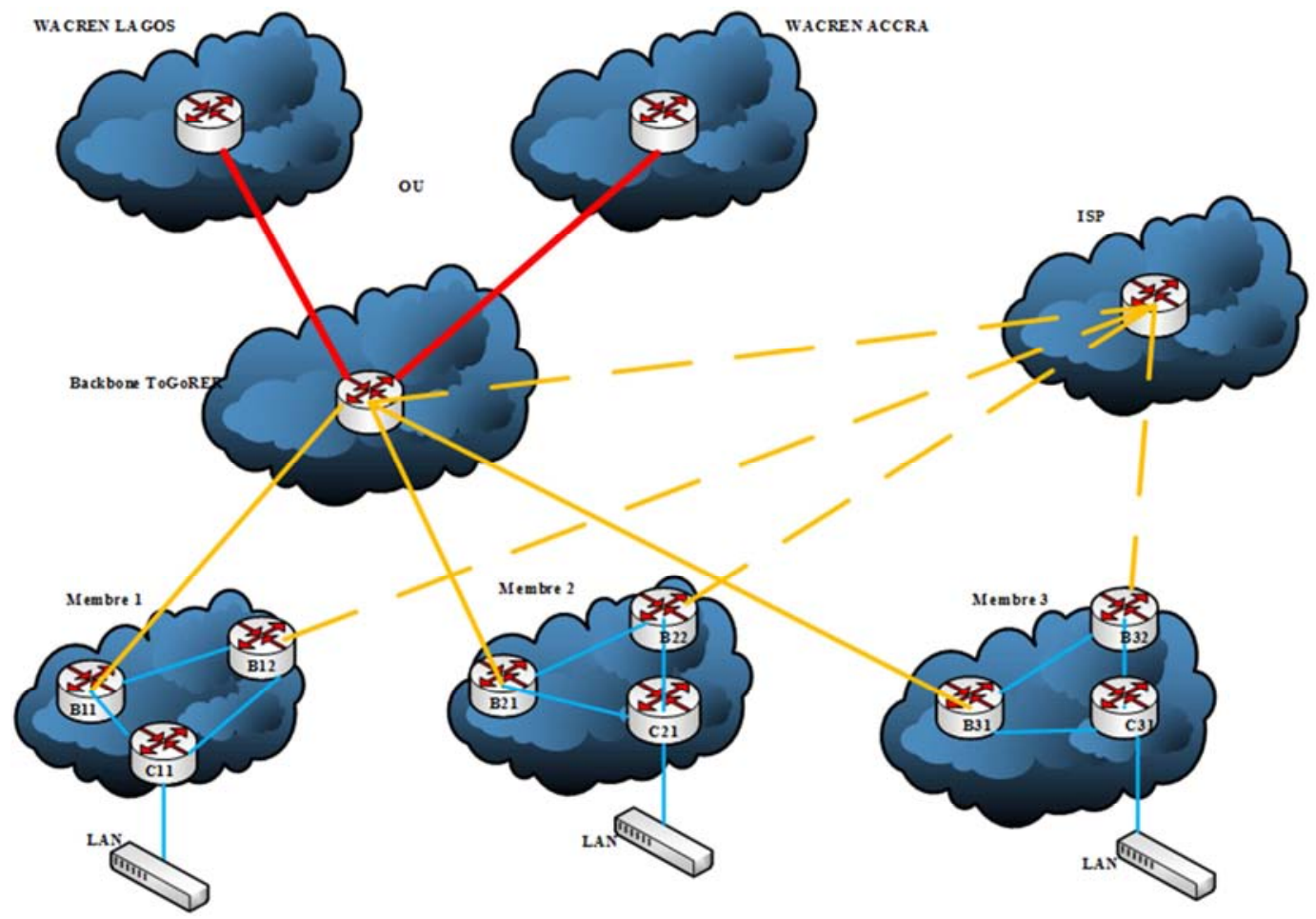

Figure 5. Direct optical fiber architecture.

The costs of realizing direct fibers are estimated globally as \$US eleven million five hundred and eighty-four thousand six hundred and sixty-eight (\$US 11584668) to carry out the direct optical fiber drawing work of the ten (10) current member institutions of TogoRER.

This amount represents only the cost of purchasing the equipment and billing for drawing of the direct optical fiber.

This price does not include the acquisition of the equipment (like switches and routers) required to put the network in operational condition.

These estimated costs are based on the proposals of the various calls for tenders for fiber drawing. This does not take into account other institutions that will be future members. As can be seen, it is extremely high funding.

A second topology approach (Figure 6) is proposed for the national and international interconnection of TogoRER's backbone and its member institutions.

The links are made from the access routers of an IP/MPLS network of TOGOTELECOM Group, the main operator of Togo $[14,15]$.

This transmission network, which is entirely in optical fiber, will be used to carry data of TogoRER's private network. One of the advantages is that this network already exists and the optical fiber drawing to connect the member institutions is only done on the last kilometer.

Therefore it is necessary to resort to the establishment of point-to-point Virtual Private Routed Network (VPRN) tunnels must be created between the latest access routers (PE router). Thus, the operator's network is totally transparent to the exchange of information between TogoRER NOC and its members. 


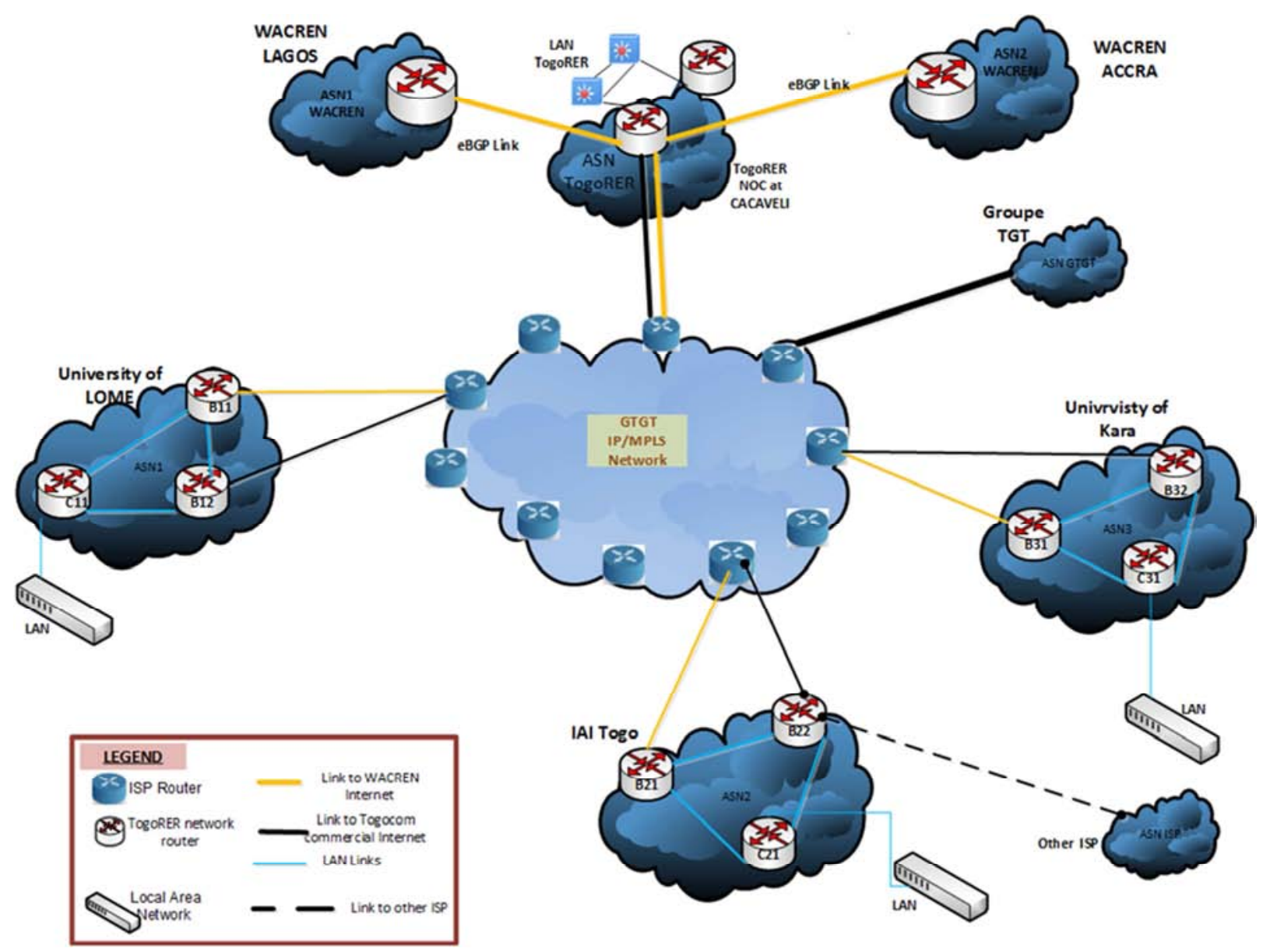

Figure 6. Architecture going by the operator (The old figure is changed to this one).

The overall amount is \$US three hundred and eighty-nine thousand five hundred (\$US 389500).

As in the previous case, this amount also represents only the cost of purchasing the equipment and billing for drawing of the optical fiber on the last kilometer of ISP Point of Presence.

This price does not include the acquisition of the equipment (like switches and routers) required to put the network in operational condition.

This service option from Togo Telecom Group network, has the advantage of being less expensive to achieve, no particular constraint and achievable within an acceptable time. So this option will be retained for implementation.

Comparative study of the advantages and disadvantages of the two previous proposals will allow us to select an architecture that will serve as a result of this study.

Table 1. Case of architecture made of direct fibers to build.

\begin{tabular}{ll}
\hline Avantages & Disadvantages \\
\hline bandwidth available as needed & $\begin{array}{l}\text { For implementation, it is necessary to have a license from ARTP (Telecom } \\
\text { regulation agency in Togo) }\end{array}$ \\
bandwidth on a link from point A to another point B is totally dedicated & $\begin{array}{l}\text { Very expensive for implementation } \\
\text { have your own fiber optic transmission network }\end{array}$ \\
\hline
\end{tabular}

Table 2. Cases of using an Operator Backbone Network.

\begin{tabular}{ll}
\hline Avantages & Disadvantages \\
\hline Relatively short implementation time & The capacity of the various links is limited by the negotiated bandwidth with the operator \\
no need for an operator license & bandwidth fluctuation on shared bandwidth links \\
$\begin{array}{l}\text { Necessary funding easier to find for implementation } \\
\text { Securing (redundancy) links is provided by the operator }\end{array}$ & be sometimes confronted to some binding decisions of the operator \\
\hline
\end{tabular}

According to the advantages and disadvantages of the two types of previous architectures, it should be noted that the best architecture in terms of cost, ease and speed of implementation is that which uses the operator's existing transmission network, in this case the Togo Telecom Group.

Thus, this architecture is the one proposed for implementation (Figure 7). 


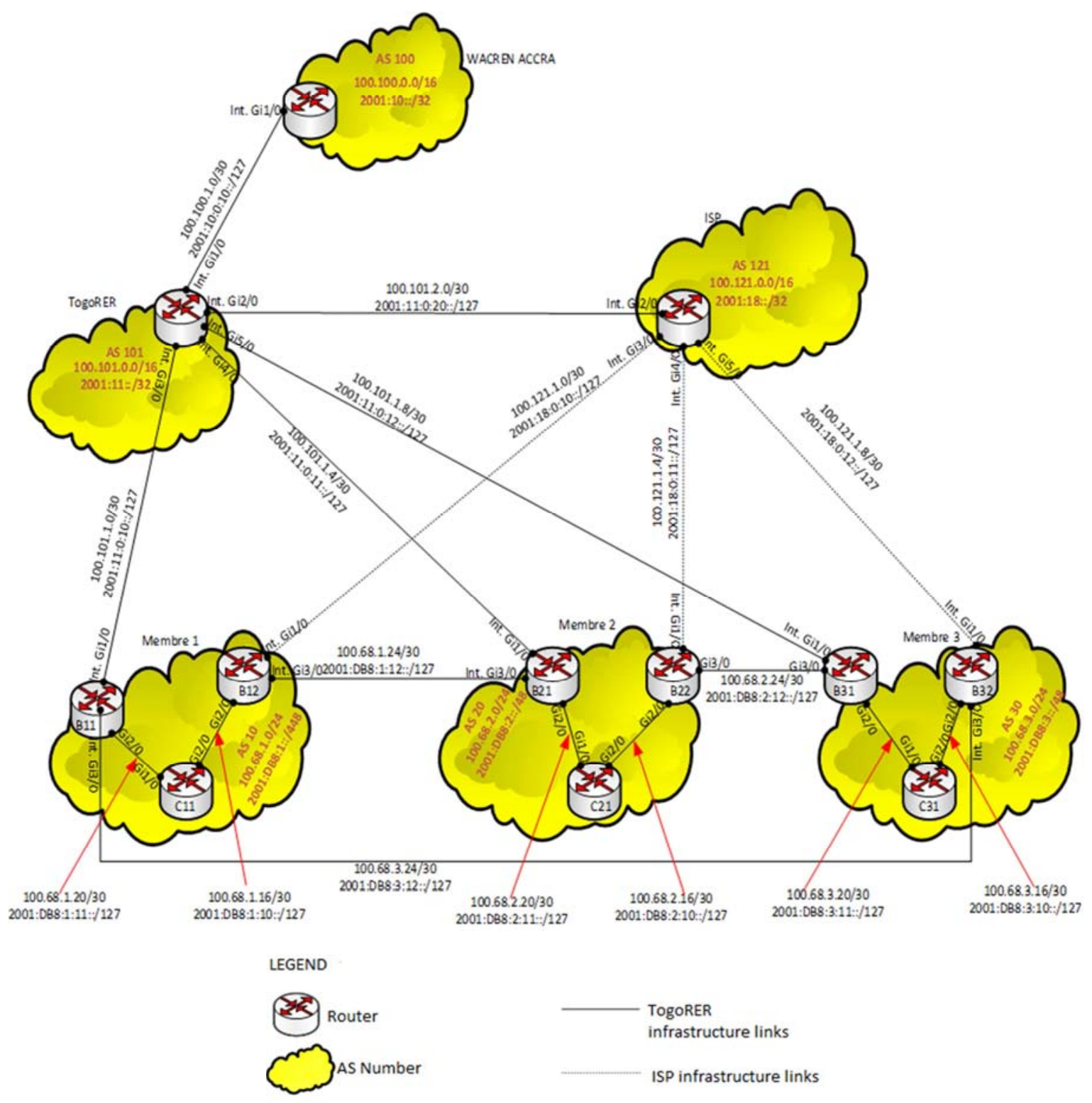

Figure 7. overview architecture of the chosen solution.

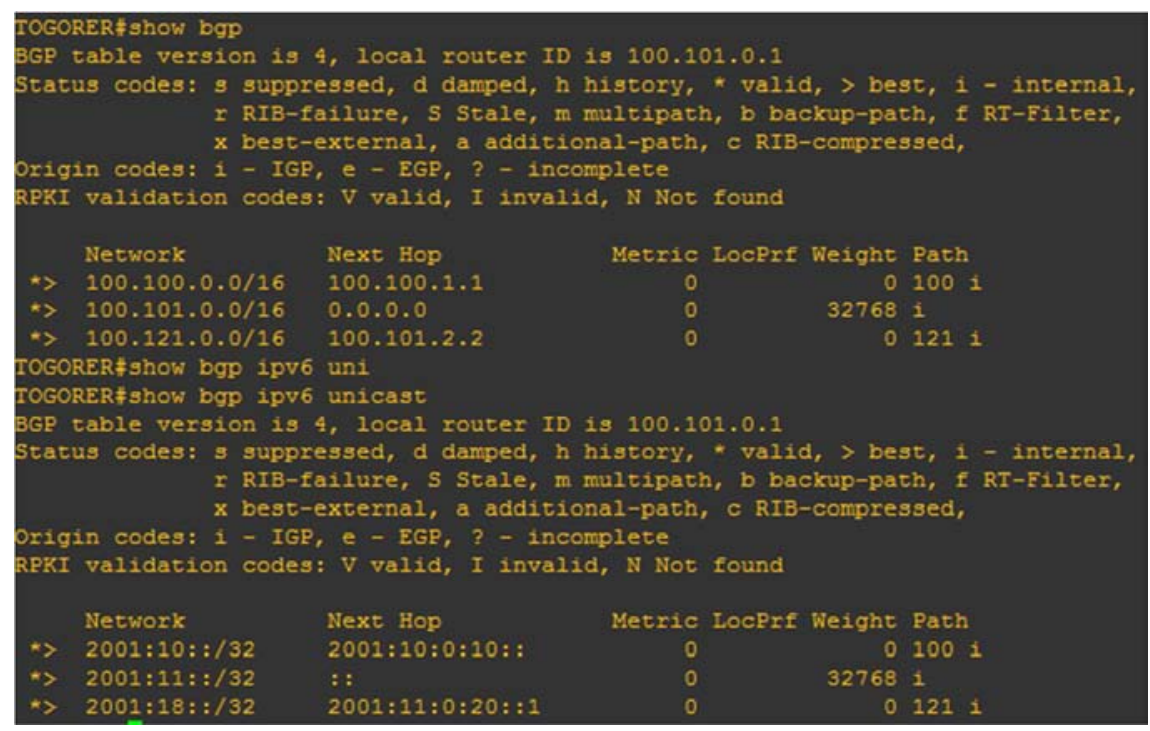

Figure 8. Connectivity tests. 


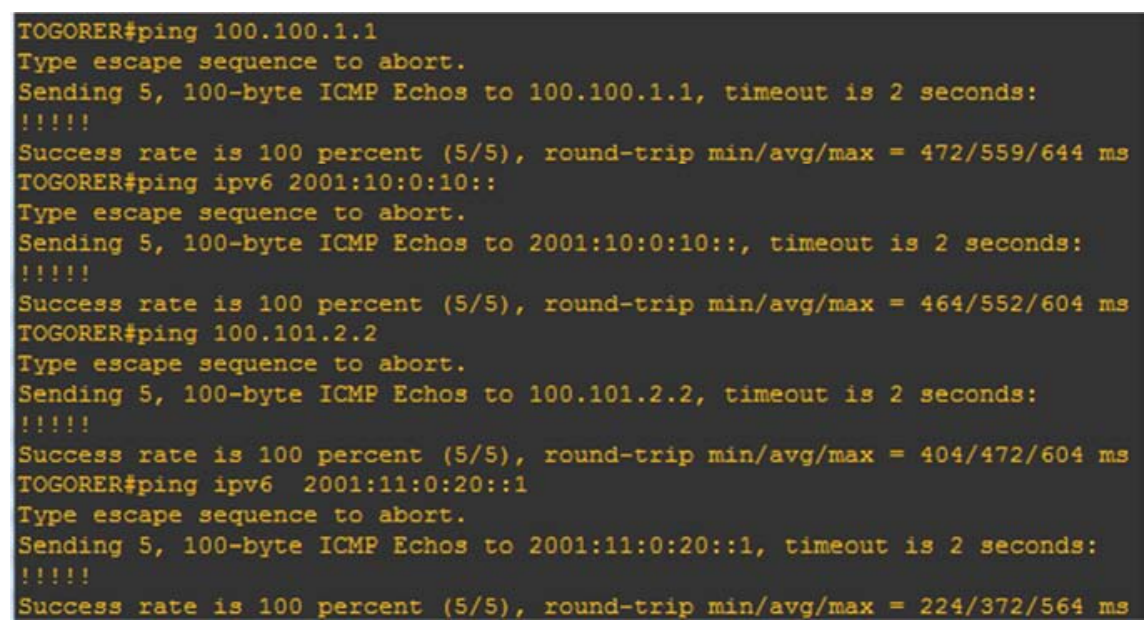

Figure 9. BGP sessions.

For the configuration purpose, the GNS3 simulator is used essentially for tests between TogoRER and his international peering (ACCRA and LAGOS).

GNS3 is a Cisco equipment simulator. This tool allows you to load real Cisco IOS and use them in full simulation on a single computer.

In order to allow full simulations, GNS3 is strongly linked with:

a Dynamips, an IOS image emulator that allows launching IOS binary images from Cisco Systems.

b Dynagen, a text-based interface for Dynamips.

GNS3 is free software that runs on multiple platforms, including Windows, Linux and Mac OS X.

After configuration of this topology in GNS3,

Simulation was done on links that will connect TogoRER to WACREN network (ACCRA and LAGOS) and the simulation consists on one side, to test both the connectivity (ping command in IPv4 and IPv6) on links from TogoRER to ACCRA and to LAGOS. On the second side, to test the establishment of BGP sessions (IPv4 and IPv6) which are necessary to the routing processes between TogoRER and ACCRA or LAGOS. The figure 8 shows that, connectivity is successful in IPv4 and IPv6 onto the both international links of TogoRER. Also the figure 9 shows how successful the BGP sessions are established in IPv4 and IPv6 between TogoRER Edge router and the neighbors of ACCRA and LAGOS. This configuration is what will be implemented in real case.

After analyzing the particular situation of Togo, according to country realities for the establishment of an education and research network, the following difficulties emerge:

a The optical fiber network already deployed in the country by different actors is even less dense, generating a total use of the rare available optical fiber;

b There are not enough operators (telecom Operators, local authorities ...) who own available optical fibers to allocate to desiring entities;

c There are then difficulties in renting fiber from operators and in addition the other major obstacle is the difficulty in financing (implementation costs and license) in case TogoRER decides to set up its own optical fibers.

In contrast to a country like France which is ahead in this domain and which began the establishment of its research and education network since 1993; where the optical fibers mesh is very important, it is easier for companies wishing to obtain fibers from operators (either a lower cost lease or sponsorship): because of the abundant availability of optical fibers, this allowed RENATER to build its research and education network by optical fiber, mainly with direct fibers, thus having a truly independent network vis-à-vis any operator.

TogoRER which is a recent structure and whose network is under construction is forced to think of another design option for its network, particular by choosing initially to pool its network to that of an already existing operator.

Hence the result of this study which led to the use of TOGO TELECOM group national backbone to carry the transmission network of TogoRER.

This is not a definitive option, because more the mesh of the optical fiber will be important in the country, TogoRER, like France [16], will be able to negotiate direct optical fibers in order to fully dispose of the total bandwidth on the interconnection links.

\section{Conclusion}

Education and research are important levers for sustainable development, the reason why governments allocate substantial budgets to these sectors. Today, these sectors are based on the need for modern and efficient means. It is with this in mind that Central and West Africa, higher education institutions are putting in place their infrastructure for their universities and research centers.

Compared to the other education and research networks ASREN, Canarie, CLARA, CARE etc..., which are already well established, that of WACREN is under construction. This is so for the specific case of TOGORER. To set up its network and meet the needs of higher education institutions, TogoRER needs at short term to choose for a cheaper 
solution by passing its traffic through an operator network due to the lack of optical fiber availability between the different members.

In the medium and long term, there will be probably abundant network of optical fiber operators.

TogoRER will then be able to solicit from these various entities, a sponsorship of education by allocating their unused fiber. Helping to achieve its direct fiber interconnections and benefit from very wide bandwidths for the promotion of education in TOGO.

\section{References}

[1] Karsenti, T. et Larose, F. (dir.) (2001). Les TIC... au cœur des pédagogies universitaires. Québec : Presses de l'Université du Québec.

[2] M. T. SECK, Insertion d'Internet dans les milieux de la recherche scientifique en Afrique de l'Ouest, Mai 1997.

[3] Schürch, D. (2002). L'intégration des technologies de l'information et de la communication dans les projets de développement de régions enclavées. Revue des sciences de l'éducation, 28(2), 435-458.

[4] M. M. Mulhanga and al, Expanding Scientific Knowledge Frontiers: Open Repositories in Developing Countries Supported by NRENs, Springer International Publishing Switzerland 2014.

[5] Willinsky, J.: The Access Principle: The Case for Open Access to Research and Scholarship. MIT Press, Cambridge (2005).

[6] R. JANZ, The NREN Business Model, 2003 https://www.casefornrens.org/Resources_and_Tools/Documen t_Library/Documents/The\%20NREN\%20Business\%20Model. pdf
[7] C Depover, $\mathrm{T}$ Karsenti, V Komis, Enseigner avec les technologies, Presses de l'Université du Québec, - 2007.

[8] M. Foley, Le rôle et le statut des réseaux nationaux d'éducation et de recherche (NREN) en Afrique, World Bank Education, Technology \& Innovation, Saber-ICT Technical Paper Series, 2016.

[9] Bjorn Pehrson \& Anders Comstedt, Connecter l'Afrique de l'ouest et du centre au réseau global d'éducation et de recherche, Etude réalisée par l'association des Universités Africaines, 2007.

[10] P. Hamilton and al, « Connectivité des institutions d'enseignement supérieur africaines. Répondre à la demande en Afrique de l'ouest et du centre ». Etude réalisée par l'association des Universités Africaines, 2007.

[11] Karsenti, T. (1999). Comment le recours aux TIC en pédagogie universitaire peut favoriser la motivation des étudiants : le cas d'un cours médiatisé sur le web. Cahiers de la recherche en éducation, 6(3), 455-484.

[12] VIENS, J., BREULEUX, A., BORDELEAU, P., ARMAND F., LEGENDRE, M-F., VASQUEZ-ABAD, J., RIOUX, S., (2001). Rapport de recherche du Collectif de recherche sur l'apprentissage collaboratif à l'aide des TIC (CRACTIC). Département d'études en éducation, Faculté des sciences de l'éducation, Université de Montréal.

[13] C. Servin, Réseaux et Télécoms, DUNOD, 2003.

[14] QoS for IP/MPLS Networks (paperback) (Anglais) Broché - 2 juin 2006 de Santiago Alvarez.

[15] NokiaEDU, R14.0 Service operation and provisioningChapter 2, Student Guide, TOS36042_V5.0-SG Edition1, 2016.

[16] F. SIMON, RENATER-5, GIP RENATER Directeur Technique FSGIP RENATER (2007). 